\title{
Using scientific evidence to guide the conservation of a highly fragmented and threatened Afrotropical forest
}

\author{
Mwangi Githiru and Luc Lens
}

\begin{abstract}
Fragmentation of forests adversely affects forest-dependent biota, and conservation biologists strive to develop a good understanding of how species respond to changes associated with habitat attrition in order to establish the best conservation strategies. The spatial structure of populations persisting in fragmented landscapes governs their response to habitat fragmentation, and hence dictates the remedial actions that will be most effective for species and habitat conservation. The Taita Hills forests of Kenya are an example of a highly fragmented Afrotropical forest ecosystem embedded in a human-dominated landscape. The spatial structure of the white-starred robin Pogonocichla stellata populations living in indigenous forests across this landscape was examined. Due to its forest dependence and widespread occurrence, the robin was used as a model species to help formulate general conservation guidelines for
\end{abstract}

forest-dependent species and their habitats within this landscape. Results from demographic, genetic and behavioural work point to a mixed spatial structure with elements of patchy population dynamics on a fine scale, and a core-satellite or source-pseudo-sink system on a broader scale. In particular, the findings underscore (1) the importance of dispersal, (2) the importance of small patches, (3) the importance of the largest patch, and (4) the processes underlying problems associated with forest disturbance. We examine the conservation implications of this information, and report on activities already initiated or planned, in line with these findings, for the Taita Hills.

Keywords Afrotropical forest, fragmentation, Kenya, Pogonocichla stellata, spatial structure, Taita Hills, whitestarred robin.

\section{Introduction}

Forest fragmentation leads to the creation of discrete habitat patches of different size and quality that contain separate local populations. These populations are connected by among-population processes (e.g. dispersal, gene flow, colonization), which can affect and/or be affected by within-population processes (e.g. birth, death, competition). The resulting spatial structure of the entire population is shaped by the amount of dispersal occurring between populations in the remnant patches, and by the disparity in local population dynamics amongst them. Resolving the nature of this spatial structure is vital when formulating conservation guidelines because it provides a conceptual tool for dealing with the interactions between within- and among-population

Mwangi Githiru ${ }^{1}$ (Corresponding author) Edward Grey Institute of Field Ornithology, Department of Zoology, University of Oxford, and National Museums of Kenya, Nairobi, Kenya. E-mail mwangi.githiru@ua.ac.be

Luc Lens Ghent University, Department of Biology, Unit of Terrestrial Ecology, Ledeganckstraat 35, B-9000 Ghent, Belgium.

${ }^{1}$ Present address: Laboratory of Animal Ecology, Department of Biology, University of Antwerp, Universiteitsplein 1, B-2610, Wilrijk, Belgium.

Received 6 May 2003. Revision requested 5 October 2003. Accepted 2 July 2004. factors (Wiens, 1996; Thrall et al., 2000). This framework ensures a process-oriented and scale-appropriate approach to conservation, explicitly focusing on amongpopulation processes that are critical for the persistence of many fragmented natural systems (Thrall et al., 2000; Lens et al., 2002).

Besides patchy populations, which are well mixed and function essentially as a single population (Harrison, 1991; Harrison \& Taylor, 1997), four main variants of populations in fragmented landscapes have been characterized: (1) classic metapopulations, (2) sourcesinks or pseudo-sinks, (3) Core-satellite (similar to mainland-island), and (4) non-equilibrium populations (see reviews in Hanski, 1991; Hanski \& Gilpin, 1991; Harrison, 1991, 1994; Wiens, 1994, 1996). The unrealistic set of assumptions underlying classic metapopulations (Levins, 1970), such as infinite number of patches and patches remaining available for recolonization following extinction, led to questions being raised about the usefulness of this category in describing and conserving real populations (Harrison, 1991; Thomas, 1994; Hanski, 1998; Opdam \& Wiens, 2002). However, some of these assumptions have since been relaxed (Hanski, 1998), and research has shown that their violation may not have serious implications for the applicability of this model for conservation (Lopez \& Pfister, 2001). When different patches within the landscape differ in their habitat 
quality, local births may exceed deaths in better habitats, with the surplus dispersing to poorer habitats; the latter thus become net importers of individuals, i.e. habitat sinks (Dias, 1996; Pulliam, 1988). Sinks could be totally dependent on immigrants for their persistence (true sinks), or only depend on them for maintaining a higher population size than would otherwise be the case (pseudo-sinks) (Pulliam \& Danielson, 1991; Watkinson \& Sutherland, 1995). The core-satellite structure differs from the source-sink system in that the satellites (or islands) do not require immigrants to maintain their current population sizes. They contain local, self-sustaining but small populations that may regularly go extinct due to stochastic causes, with immigrants from the core (or mainland) population routinely recolonizing any empty and suitable patches. Compared to satellites, therefore, sinks are often at a higher risk of extinction, having negative population growth rates in the absence of immigrants (Hanski \& Simberloff, 1997). Finally, nonequilibrium populations are those undergoing landscape-level declines, and will go extinct regionally, across all patches, if no intervention, such as proactive management, occurs (Harrison, 1991). An additional loss of critical habitat could precipitate the degeneration of any of the three preceding types of subdivided populations into this category.

Although metapopulations have been defined as explicitly involving colonization and extinction processes, with each population being at risk of extinction (Moilanen \& Hanski, 1998), variation in population traits (size and other demographic attributes) and patch features (size, quality and degree of isolation) implies that probabilities of survival will often differ amongst subpopulations (Blondel \& Lebreton, 1996). This gives rise to a continuum of metapopulation scenarios ranging from a patchy population to non-equilibrium populations (Harrison, 1991; Newton, 1998). Hence, although the spatial structures above are discretely described, it is likely that real populations will be intermediate cases, exhibiting a mixture of elements characteristic of several systems (Harrison \& Taylor, 1997). For instance, there may be metapopulations where local populations fluctuate relatively independently of each other with little turnover, only exchanging low to moderate numbers of immigrants. In this case, lack of turnover notwithstanding, the metapopulation structure plays a vital stabilizing effect at the regional level (Harrison \& Taylor, 1997).

In this paper, we present conservation implications emanating from the findings of a study examining the spatial structure of seven subpopulations of the whitestarred robin Pogonocichla stellata in the Taita Hills forest fragments of Kenya. Demographic, behavioural and genetic aspects of the robin were studied in this highly fragmented and threatened landscape in order to discern the status of individual populations, as well as how they are associated with each other. Conservation of these fragments, which contain several endemic and threatened populations of both flora and fauna, is urgently required (Bennun \& Njoroge, 1999). Large-scale forest loss and encroachment over the last few decades have reduced the once extensive indigenous forests to small remnants on hilltops, while denuded hillsides that were unsuccessfully cultivated after clearing natural vegetation have been reforested with exotic trees (Beentje \& Ndiang'ui, 1988). These remnants are only protected as Forest Reserves under jurisdiction of the Forest Department, a category that permits considerable resource exploitation, with little investment in protection (Lovett \& Wasser, 1993). Thus, multiple threats persist, including exotic tree plantations, clearance for agriculture and the ever-increasing demands for fuelwood and building poles. This is compounded by the fact that the forests are poorly appreciated by the custodians, decision makers and stakeholders, despite their importance for biodiversity and as water catchments (Bennun \& Njoroge, 1999). Studying the robin was both desirable and justified because of its forest dependence and widespread distribution across the landscape (Bennun et al., 1996; Lens et al., 2002). Therefore, it could furnish ample sample sizes and enable work to be done at a broad spatial scale, whilst providing insights that would be of wide applicability for forest dependent species in general. Taita Hills' forest endemics, such as the Critically Endangered Taita thrush Turdus helleri, could not be directly used for this purpose due to their absence from several of the forest patches (Lens et al., 2002).

\section{Study species and study site}

The white-starred robin $P$. stellata (Family Turdidae) is a forest-dependent bird, resident in montane forests of eastern to southern Africa (Keith et al., 1992; Bennun et al., 1996). Of the nine known races, six occur in Kenya and northern Tanzania; sub-species helleri is confined to the Taita Hills and Mt. Kasigau (Moreau, 1951; Keith et al., 1992; Zimmerman et al., 1996). It forages at all levels in the forest, most frequently in the undergrowth and at ant trails, but also tosses leaf litter, gleans foliage, makes aerial sallies to capture flying prey and ascends into the canopy for small fruits, e.g. Rhus sp., when available (Oatley, 1982; Willis, 1985; Keith et al., 1992). It is territorial and apparently monogamous (Zimmerman et al., 1996).

The Taita Hills lie in south-eastern Kenya at $03^{\circ} 20^{\prime} \mathrm{S}$, $38^{\circ} 15^{\prime} \mathrm{E}$, c. $150 \mathrm{~km}$ inland from the coast, and cover an area of c. $250 \mathrm{~km}^{2}$ (Brooks et al., 1998). Geologically, they are the northernmost part of the Eastern Arc mountains (Lovett, 1986; Lovett \& Wasser, 1993), a global biodiversity hot spot (Myers, 1990; Mittermeier et al., 1998) and part of the Tanzania-Malawi Mountains Endemic 
Bird Area (Stattersfield et al., 1998). Being a recognized Important Bird Area, they are among the highest priorities for biodiversity conservation in Kenya (Lovett \& Wasser, 1993; Brooks et al., 1998; Bennun \& Njoroge, 1999). The present landscape consists of three distinct isolates, Dabida, Mbololo and Sagala, each containing a number of fragments (Githiru, 2003). This study was conducted in Dabida, the main isolate. The hill has nine forest patches: Ngangao (c. 135 ha), Chawia (c. 95 ha), Fururu (c. 8 ha), Ndiwenyi (c. 4 ha), Macha (c. 2 ha), Mwachora (c. 2 ha), Yale (c. 2 ha), Vuria (c. 2 ha) and Kichuchenyi (c. 1 ha) (area estimates based on Global Positioning System measurements). Data were collected in seven of the nine patches, excluding Kichuchenyi (small and highly disturbed) and Vuria (for logistical reasons). The patches were grouped into three size classes, Ngangao (large), Chawia (medium), with the other five being small; five 3-ha plots were randomly selected in the large and medium fragments for study, and the small patches were treated as single plots. Habitat quality data based on vegetation characteristics and structure (Wilder et al., 2000) and on plant species richness and diversity (Githiru, 2000) suggest the large fragment was the highest quality habitat, with well developed three-strata forest and the greatest floral diversity, and the medium and small patches were of lower quality and had higher disturbance levels. The medium patch was undergoing the highest level of human incursions and disturbance during the period of this study (M. Githiru \& L. Lens, pers. obs.).

\section{Evaluation of spatial structure}

Rates of survival (the probability that an animal is alive and remains in the study area and hence is available for recapture), population change $\left(\lambda=\mathrm{N}_{\mathrm{t}+1} / \mathrm{N}_{\mathrm{t}}\right.$, where $\mathrm{N}$ is the population size and $t$ is time), and recruitment or individual turnover (the probability that an individual present in the population at time $i$ was present at time $i-1$ ) were estimated using programme MARK (White \& Burnham, 1999) from capture-recapture histories of 403 individual robins captured between 2000 and 2002 (Githiru, 2003). In all, there were six capture-recapture sessions in which each captured bird was uniquely colour-ringed and its blood sampled. Modelling revealed that the survival rates and rates of population change did not differ significantly amongst the different subpopulations (M. Githiru \& L. Lens, unpubl. data). However, recruitment rates differed, with the population in the large patch showing lower recruitment than populations in the medium and small patches (M. Githiru \& L. Lens, unpubl. data). Because programme MARK does not distinguish between dispersal and death in its estimation of survival, differences in recruitment patterns not reflected in the survival patterns hint at different processes occurring in different fragments. The lower probability of finding new individuals in the large patch, compared to the rest, suggested that this fragment was more stable, with low within-patch mortality creating lesser chance for turnover of individuals. Hence, most of the new potential recruits probably dispersed out of this fragment, making dispersal-related mortality more important than within-patch mortality. In contrast, higher turnover of individuals in the other patches implied they suffered higher within-patch deaths (which precipitated the replacements) than the large fragment.

This inference is based on the assumption that potential recruits were present in all fragments. Yet, in addition to survival, both differential productivity and availability of immigrants could affect the probability of finding new birds in a population. We used the ratios of juvenile to adult birds captured in the study plots at or immediately after the breeding season (before natal dispersal) as an index of reproductive success. We compared juvenile:adult ratios amongst the fragments using contingency tables and log linear analysis (SPSS, 2001) and found that the large and small patches had significantly higher productivity than the medium patch (M. Githiru \& L. Lens, unpubl. data). This finding was collaborated by results of a male-removal experiment that demonstrated a scarcity of females in this patch, and by an artificial nest experiment that revealed significantly higher rates of predation in the medium fragment (Githiru, 2003). Thus, combining the knowledge from the recruitment data with these survival and productivity results suggests that mortality in the large patch was more from dispersal than within-patch death (high reproductive success and low recruitment), in the medium patch primarily from within-patch predation (low reproductive success and high recruitment) and intermediate for the small patches (high reproductive success and high recruitment).

Given these findings, and because all the populations were relatively stable, we predicted that the medium patch would require the highest immigration levels, the large fragment the least, with the small patches being intermediate. We assessed dispersal patterns using capture-recapture data and genetic techniques. Seven microsatellite primers were used in the genotyping of at least 30 individuals from each remnant patch, which enabled estimation of gene flow and effective dispersal rates, as well as an evaluation of the population structure (i.e. differentiation amongst subpopulations). Birds in the medium and small patches had higher numbers of alleles and heterozygosity than the large patch, indicative of an assortment of individuals from different populations (Galbusera et al., 2004). This is what one would expect if there is higher emigration than immigration in the large patch compared to the others. Only one juvenile individual, a female disperser from the large 


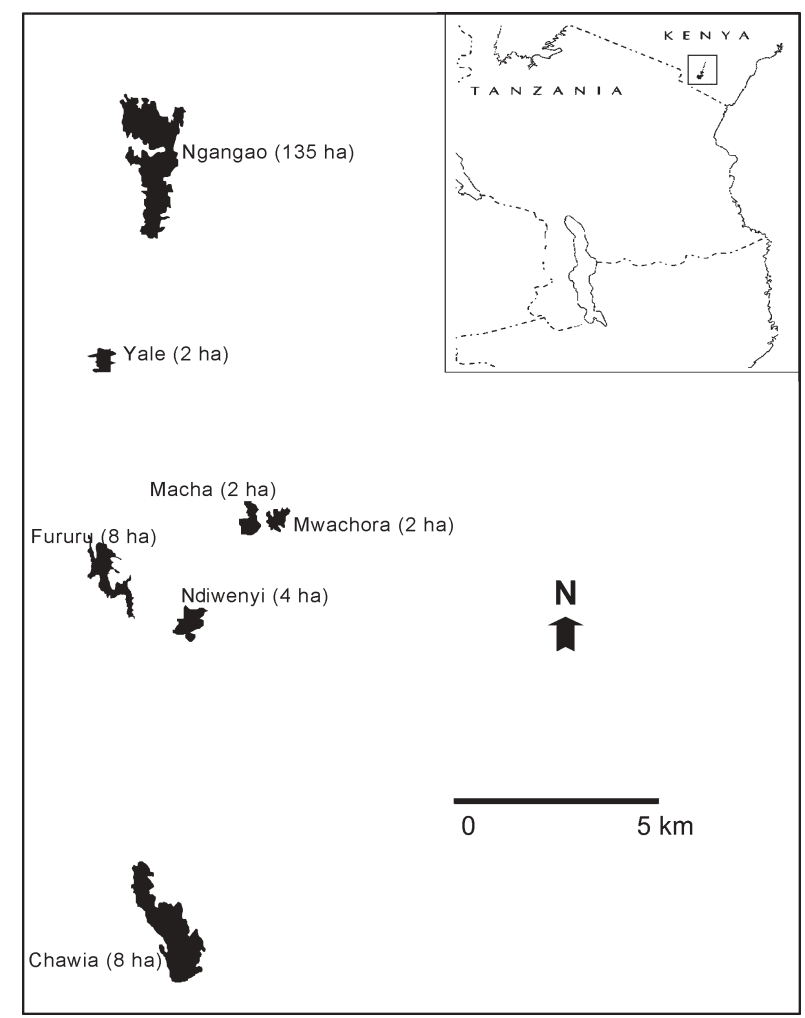

Fig. 1 The seven forest fragments studied, and their approximate sizes in ha, in the Taita Hills landscape of Kenya. Fragment illustrations depict a relative rather than absolute size. The small box in the inset figure indicates the location of the Taita Hills in south-east Kenya.

to the medium patch, was recaptured in a different fragment from its natal patch during the study period. Additionally, the medium and small patches were more closely associated with each other than with the large patch (Galbusera et al., 2004), suggesting that the small patches provided more dispersers to the medium patch than the large fragment. This is consistent with their geographical setting (Fig. 1), and implies that the dispersers from the large patch were either mainly dispersing into fragments not included in this study, or suffered higher mortality during dispersal. The former is less likely because we studied most of the forest fragments in this landscape, and the latter is more likely due to topographic features, especially the presence of a town between the large patch and most of the other patches (Brooks et al., 1998) that could have inhibited dispersal. Finally, capture-recapture data suggest a high interpatch dispersal within a cluster of the small patches (Lens et al., 1999), which could produce and maintain the high levels of allelic richness and heterozygosity found in these patches (Galbusera et al., 2004).

Four key points emerge: (1) importance of dispersal, especially for maintaining the population dynamics within the medium and small patches, (2) importance of the small patches both as a possible key source of migrants to the medium patch and for maintaining overall genetic variation, (3) importance of the large patch as a stable independent population and a refuge and future source of immigrants, and (4) evidence that the ongoing forest degradation within the medium patch is having adverse effects even though its perimeter remains relatively intact. Overall, these findings point to a hierarchical multi-layered spatial structure, with a likely source-pseudo-sink system at the broad landscape scale (with the large and small fragments being largely potential sources, the medium patch a pseudo-sink), and patchy population dynamics at the finer scale (the cluster of small patches) (Fig. 1).

\section{Discussion}

The main conservation consequences of this multilayered spatial structure are twofold. Firstly, it emphasizes that consolidating efforts to conserve the population in the large patch, as a refuge, is crucial to ensuring the long-term survival of the robin population regionally. Secondly, it stresses the importance of maintaining adequate inter-fragment dispersal, crucial for sustaining the local population dynamics in the medium and small patches. Thus, even without complete population turnovers, i.e. explicit extinction and recolonization, this metapopulation structure has a vital stabilizing effect at the regional level, both in the short- and longterm (Harrison \& Taylor, 1997).

Based on this knowledge, we can offer conservation guidelines for this landscape from two perspectives. Firstly, related to changing land uses, and secondly, related to seeking better legal status, law enforcement and lifestyle alternatives. We stress the importance of addressing these from a holistic rather than individual point of view in order to reap the synergistic benefits.

\section{Changing land uses}

These results highlight the importance of diverting the conservation focus from the Forest Reserves themselves to include activities outside the Reserves, particularly different land uses. Land use patterns and other activities outside the protected areas are crucial, both in maintaining general landscape connectivity (important for dispersal) as well as minimizing any direct effects of the edge on the forest biota (Opdam \& Wiens, 2002). Landscape-level Geographical Information System maps for the Taita Hills have only recently become available (Taita Hills Biodiversity Project, Belgium). These will enable identification of dispersal routes and populations that warrant specific protection. More generally, introducing and fostering activities such as agroforestry in this area would simultaneously address socioeconomic 
and ecological problems, by providing alternative fuelwood and fodder while reducing edge effects and promoting dispersal. This is the integrated landscape management notion that unites the principles of metapopulation theory, landscape ecology, corridors and buffer areas (Saunders et al., 1991; Wiens, 1996).

Implementation of such recommendations would stimulate a more balanced and self-sustaining landscape mosaic, providing basic goods and services to the rural human population, which is key to poverty alleviation, while maintaining the habitats and ecosystem functions that are required to provide services to the people. In the Taita Hills a small group of individuals living around some of the fragments have shown a keen interest in environmental issues and seem willing to learn more about the forest and do more for its preservation (M. Githiru \& L. Lens, pers. obs.). There are hurdles to be overcome, particularly in keeping such a group organized and motivated in the long-term. Future conservation efforts should be focused on promoting their organization and capacity to influence environmental issues in this region. To achieve this there has to be some external financial input so that the group members are not expected to incur any personal expenses to further conservation, especially in the short-term, because they are unlikely to have any spare finances for such activities. Initiating indigenous-tree nurseries for agroforestry and promoting prudent fuelwood collection and use are possible target activities for these groups.

\section{Legal status, law enforcement and seeking alternatives}

This study underlines the urgent need to provide better legal protection to these forest patches. Despite their small sizes, all the forest remnants in this landscape are still important for biodiversity, as well as for maintaining the living standards of the local Taita people by providing their basic fuel and water needs. However, these forests are currently only protected as Forest Reserves, a category that permits substantial utilization, has minimal investment for protection (Lovett \& Wasser, 1993), and is easily abused for political and/or economic ends. These Forest Reserves need to be upgraded to a conservation category that confers improved legal protection. This would not only signal the Government's commitment, but also enable the forest guards to protect them more effectively. Together with this, increased investment towards their protection is required, not least because of its potential for provision of better training opportunities and salaries for the forest guards. Knowledgeable and motivated guards are vital in the success of any conservation venture as a link between the local people, conservation biologists and the Government. The onus is on conservation biologists working in this region to collate the scientific evidence, translate it into clear arguments and present it to the relevant Kenyan environmental authorities to stimulate dialogue. This will draw in the Government in future research work, which will make practical application of findings easier (Reid \& Mace, 2003).

There is also a need for better recognition at the local level. In particular, education initiatives need to be developed to raise the awareness of the local people, especially in schools. Although some education initiatives were initiated in a pilot study (Githiru, 2003), they need to be further developed so that they reach more schools and interested groups, as well as being more sustained. Addition of appropriate conservation-related information to school syllabi may have the most effective longterm effect. The combination of desirable land uses in the surrounding landscape mosaic, proper legal protection, an enlightened local public, and motivated and knowledgeable guards is the best hope for the long-term conservation of the Taita Hills.

\section{Acknowledgements}

We thank Dr W. Cresswell and Prof. C. Perrins for their comments on an earlier draft, and Drs A. Balmford and M. Whittingham for insightful discussions that moulded the nature of this article. We also thank two anonymous reviewers for helpful criticism of an earlier version of this manuscript, and B. Amakobe and M. Chovu for their help with fieldwork. The Rhodes Trust in Oxford, UK, and James Lynch Conservation Biology Fund at the Smithsonian Environmental Research Center, US, provided financial support.

\section{References}

Beentje, H.J. \& Ndiang'ui, N. (1988) An ecological and floristic study of the Taita Hills, Kenya. Utafiti, 1, 23-66.

Bennun, L., Dranzoa, C. \& Pomeroy, D. (1996) The forest birds of Kenya and Uganda. Journal of the East African Natural History Society, 85, 23-48.

Bennun, L.A. \& Njoroge, P. (1999) Important Bird Areas in Kenya. East African Natural History Society, Nairobi, Kenya.

Blondel, J. \& Lebreton, J.-D. (1996) The biology of spatially structured populations: concluding remarks. Acta Oecologica, 17, 687-693.

Brooks, T., Lens, L., Barnes, J., Kihuria, J.K. \& Wilder, C. (1998) The conservation status of the forest birds of the Taita Hills, Kenya. Bird Conservation International, 8, 119-139.

Dias, P.C. (1996) Sources and sinks in population biology. Trends of Ecology and Evolution, 11, 326-330.

Galbusera, P., Githiru, M., Lens, L. \& Matthysen, E. (2004) Genetic equilibrium despite habitat fragmentation in an Afrotropical bird. Molecular Ecology, 13, 1409-1421.

Githiru, M. (2000) Avian frugivory and seed dispersal in some of the Taita Hills forest fragments. MSc thesis, Kenyatta University, Nairobi, Kenya. 
Githiru, M. (2003) Endemic forest birds of the Taita Hills: using a model species to understand the effects of habitat fragmentation on small populations. DPhil thesis, University of Oxford, Oxford, UK.

Hanski, I. (1991) Single-species metapopulation dynamics: concepts, models and observations. Biological Journal of the Linnean Society, 42, 17-38.

Hanski, I. (1998) Metapopulation dynamics. Nature, 396, 41-49.

Hanski, I. \& Gilpin, M. (1991) Metapopulation dynamics: brief history and conceptual domain. Biological Journal of the Linnean Society, 42, 3-16.

Hanski, I. \& Simberloff, D. (1997) The metapopulation approach, its history, conceptual domain, and application to conservation. In Metapopulation Biology: Ecology, Genetics, and Evolution (eds I. Hanski \& M. Gilpin), pp. 5-26. Academic Press, San Diego, USA.

Harrison, S. (1991) Local extinction in a metapopulation context: an empirical evaluation. Biological Journal of the Linnean Society, 42, 73-88.

Harrison, S. (1994) Metapopulations and conservation. In Large Scale Ecology and Conservation Biology (eds P.J. Edwards, R.M. May \& N.R. Webb), pp. 111-128. Blackwell Scientific Publications, Oxford, UK.

Harrison, S. \& Taylor, A.D. (1997) Empirical evidence for metapopulation dynamics. In Metapopulation Biology: Ecology, Genetics, and Evolution (eds I. Hanski \& M. Gilpin), pp. 27-42. Academic Press, San Diego, USA.

Keith, S., Urban, E.K. \& Fry, C.H. (1992) The Birds of Africa. Academic Press, London, UK.

Lens, L., Adriaensen, F. \& Matthysen, E. (1999) Dispersal studies in recently and historically fragmented forests: A comparison between Kenya and Belgium. In Proceedings of the 22nd International Ornithological Congress (eds N. Adams \& R. Slotow), pp. 2480-2491. BirdLife South Africa, Durban, South Africa.

Lens, L., Van Dongen, S., Norris, K., Githiru, M. \& Matthysen, E. (2002) Avian persistence in fragmented rainforest. Science, 298, 1236-1238.

Levins, R. (1970) Extinction. Lectures on Mathematics in the Life Sciences, 2, 75-107.

Lopez, J.E. \& Pfister, C.A. (2001) Local population dynamics in metapopulation models: implications for conservation. Conservation Biology, 15, 1700-1709.

Lovett, J.C. (1986) The Eastern Arc forests of East Africa. Kew Magazine, 2, 83-87.

Lovett, J.C. \& Wasser, S.K. (1993) Biogeography and Ecology of the Rainforests of Eastern Africa. Cambridge University Press, Cambridge, UK.

Mittermeier, R.A., Myers, N. \& Thomsen, J.B. (1998) Biodiversity hotspots and major tropical wilderness areas: approaches to setting conservation priorities. Conservation Biology, 12, 516-520.

Moilanen, A. \& Hanski, I.A. (1998) Metapopulation dynamics: effects of habitat quality and landscape structure. Ecology, 79, 2503-2515.

Moreau, R.E. (1951) Geographical variation and plumage sequence in Pogonocichla. Ibis, 93, 383-401.

Myers, N. (1990) The biodiversity challenge: expanded hotspots analysis. Environmentalist, 8, 243-256.

Newton, I. (1998) Population Limitation in Birds. Academic Press, San Diego, USA.

Oatley, T.B. (1982) The starred robin in Natal, Part 2: annual cycles and feeding ecology. Ostrich, 53, 193-205.

Opdam, P. \& Wiens, J.A. (2002) Fragmentation, habitat loss and landscape management. In Conserving Bird Biodiversity:
General Principles and their Application (eds K. Norris \& D.J. Pain), pp. 202-223. Cambridge University Press, Cambridge, UK.

Pulliam, H.R. (1988) Sources, sinks, and population regulation. American Naturalist, 132, 652-661.

Pulliam, H.R. \& Danielson, B.J. (1991) Sources, sinks, and habitat selection: a landscape perspective on population dynamics. American Naturalist, 137, S51-S66.

Reid, W.V. \& Mace, G.M. (2003) Taking conservation biology to new levels in environmental decision-making. Conservation Biology, 17, 943-945.

Saunders, D.A., Hobbs, R.J. \& Margules, C.R. (1991) Biological consequences of ecosystem fragmentation: a review. Conservation Biology, 5, 18-32.

SPSS (2001) SPSS for Windows. SPSS, Inc., Chicago, USA.

Stattersfield, A.J., Crosby, M.J., Long, A.J. \& Wege, D.C. (1998) Endemic Bird Areas of the World: Priorities for Biodiversity Conservation. BirdLife International, Cambridge, UK.

Thomas, C.D. (1994) Extinction, colonization, and metapopulations: environmental tracking by rare species. Conservation Biology, 8, 373-378.

Thrall, P.H., Burdon, J.J. \& Murray, B.R. (2000) The metapopulation paradigm: a fragmented view of conservation biology. In Genetics, Demography and Viability of Fragmented Populations (eds A.G. Young \& G.M. Clarke), pp. 75-95. Cambridge University Press, Cambridge, UK.

Watkinson, A.R. \& Sutherland, W.J. (1995) Sources, sinks and pseudo-sinks. Journal of Animal Ecology, 64, 126-130.

White, G.C. \& Burnham, K.P. (1999) Program MARK: survival estimation from populations of marked animals. Bird Study, 46, S120-S139.

Wiens, J.A. (1994) Habitat fragmentation: island v. landscape perspectives on bird conservation. Ibis, 137, S97-S104.

Wiens, J.A. (1996) Wildlife in Patchy Environments: Metapopulations, Mosaics and Management. Island Press, Washington, DC, USA.

Wilder, C.M., Brooks, T.M. \& Lens, L. (2000) Vegetation structure and composition of the Taita Hills forests. Journal of the East African Natural History Society, 87, 181-187.

Willis, E.O. (1985) East African Turdidae as safari ant followers. Gerfaut, 75, 130-153.

Zimmerman, D.J., Turner, D.A. \& Pearson, D.J. (1996) Birds of Kenya and Northern Tanzania. Russell Freedman Books, Halfway House, South Africa.

\section{Biographical sketches}

Mwangi Githiru has also studied the effects of forest fragmentation on forest regeneration with respect to avian seed dispersal, and has initiated several small-scale education initiatives in local schools seeking to develop general environmental awareness. In addition to continued involvement in long-term research in the Taita Hills, he is interested in incorporating conservation activities and principles into rural development projects in developing countries.

Luc Lens's main research interests include the study of behaviour in spatially structured populations of vertebrates and invertebrates, the study of bird-plant interactions, and studying developmental stability as an early warning system for conservation applications. His research spans both the tropical and temperate zones. 